\title{
EXPERIÊNCIAS DA GESTÃO ESCOLAR VISANDO À FORMAÇÃO DE FUNCIONÁRIOS ADMINISTRATIVOS
}

http://dx.doi.org/10.5902/2318133865003

\author{
Caio Cesar Silva Nascimento ${ }^{1}$
}

\begin{abstract}
Resumo
Neste trabalho buscou-se refletir acerca de algumas experiências de cunho formativo destinadas à funcionários administrativos de uma escola de educação para o trabalho. Por meio do discurso e da prática social de que todos os que atuam nessa instituição são educadores em suas atitudes, as equipes administrativas - atendimento, biblioteca, secretaria, manutenção, recursos humanos, limpeza, tecnologia da informação e assistentes de coordenação - vivenciaram processos formativos visando a contribuir para a instalação de um espaço escolar democrático. Nesse caminho, apresentar-se-ão algumas propostas da equipe gestora que fomentaram o trabalho das equipes administrativas enquanto trabalhadores em escola. Para além das vivências, serão evidenciados os processos que impulsionaram essa sequência formativa. A pergunta norteadora deste trabalho foi a seguinte: como a formação das equipes administrativas pode subsidiar para que todos os setores da escola sejam espaços de aprendizagem?

Palavras-chave: formação em serviço; trabalhadores em educação; gestão escolar; funcionários administrativos da escola.
\end{abstract}

\section{EXPERIENCES OF SCHOOL MANAGEMENT AIMING AT THE TRAINING OF ADMINISTRATIVE EMPLOYEES}

\begin{abstract}
This work intends to reflect on some formative experiences aimed at administrative employees of a school of education for work. Through the discourse and social practice that everyone who works at this institution are educators in their attitudes, such as administrative teams - service, library, secretariat, maintenance, human resources, cleaning, information technology and coordination assistants - experienced formative processes contribute to the construction of a democratic school space. In this way, some proposals from the management team that promoted the work of the administrative teams as workers in the school will be presented. In addition to the experiences, the processes that drove this formative sequence will be highlighted. The guiding question of this work is the following: how can the formation of administrative teams help to ensure that all sectors of the school are spaces for learning?

Key-words: in-service training; education workers; school management; school administrative staff.
\end{abstract}

\footnotetext{
${ }_{1}$ Serviço Nacional de Aprendizagem Comercial/SP, Brasil. E-mail: caionasser1@gmail.com. 


\section{Introdução}

osé Pacheco manifestou, numa entrevista (Cimeac, 2016), que as escolas são

$\int$ feitas de pessoas e é nessas pessoas que todo sistema educacional deve focar. Sob este prisma pode-se afirmar que todos os funcionários de uma escola merecem atenção em seus processos formativos, no desenvolvimento de seu potencial e de suas capacidades. Entretanto, como os setores administrativos não atuam diretamente na atividade fim educacional, ou seja, na prática de sala de aula, pode haver inclinação para que não sejam contempladas suas participações e contribuições em encontros pedagógicos, reuniões com responsáveis por estudantes, conselhos de turma, planejamento anual, atividades e ações do projeto político-pedagógico, enfim, em grande parte dos eventos que estão no escopo da vida escolar.

No Serviço Nacional de Aprendizagem Comercial do Estado de São Paulo Senac/SP -, instituição focada na educação profissional em que me encontro profissionalmente, há um interesse em comum: continuar construindo uma escola de educação para o trabalho dinâmica, democrática e de qualidade. Há muito empenho de todos os setores para a escola funcione da melhor maneira possível e as equipes têm formações constantes para isso, sejam elas sobre metodologias ativas, sobre planejamento escolar e pedagógico, sobre inclusão e diversidade, sobre avaliação, entre outras temáticas que emergem no campo educacional. Sem embargo, existe ainda um longo caminho a percorrer repleto de atravessamentos cotidianos, seja pela escassez do tempo destinado ao planejamento das atividades, seja pela antecedência que outras demandas administrativas e imprevistos tomam. Pode tornar-se ainda menos relevante à escola, quando essas ações se direcionam aos funcionários que não são docentes.

Neste artigo pretende apresentar e refletir sobre a formação em serviço de funcionários administrativos de uma escola do Senac/SP. Para tanto, serão abordados alguns princípios da atuação do coordenador pedagógico, a organização e a operacionalização das ações formativas focadas nas equipes administrativas e alguns referenciais teóricos que dialogam com os debates centrais deste trabalho. Por fim, apresentar-se-ão alguns avanços na prática escolar dessa escola facilitados por atividades de cunho educativo aos funcionários que não são docentes.

\section{O dinamismo no cotidiano de uma instituição escolar}

A escola é um espaço em constante transformação, haja vista a revitalização de seus documentos, seus processos, as leis e as medidas provisórias que a regem e 0 próprio funcionamento das instituições educacionais, repleto de dinamismo. Pode ser traduzida como um local em permanente produção de sentidos para os que nela estão implicados, sejam esses alunos ou funcionários. Tendo como ponto de partida a escola enquanto espaço vivo e mutável, pode-se inferir que as equipes que citarei nesse trabalho também produzem a escola como ela é.

Aponto a existência de duas instâncias diferenciadas nessa instituição escolar: a pedagógica - representada pelos monitores de educação e professores - e a administrativa - composta pelos gestores e pelas equipes administrativas. Pode-se 
deduzir que essas duas instâncias interferem no cotidiano escolar, seja na tomada de decisões, na criação do quadro de horários das turmas ou na abordagem didática de uma aula.

A dinâmica viva da instituição sucede no dia a dia dos funcionários das áreas administrativas. A equipe de secretaria lida com situações atípicas de estudantes e procedimentos que são constantemente atualizados oriundos das legislações educacionais e, principalmente, de acontecimentos das vidas de alunos e que ainda não existem respostas ou encaminhamentos prontos. Isso significar dizer que as áreas administrativas tratam de questões burocráticas, entretanto, se relacionam com os alunos e docentes, no sentido de que também orientam no que tange a vida escolar dos educandos. Portanto, necessitam refletir sobre as orientações e dialogar com os estudantes, afinal, intervém sobre as vidas dessas pessoas no âmbito educacional.

Com base no pensamento de Schmidt (1989) e os apontamentos acerca das duas instâncias de uma instituição escolar - pedagógica e administrativa -, pode-se entender que a escola compreende uma comunidade de aprendizagem, por meio das relações e dos vínculos criados nos corredores, na sala da direção, na coordenação, na biblioteca e nos espaços de convivência. A troca de informações entre alunos e funcionários é constante. Nesse sentido, cabe uma indagação: como a escola forma e educa os funcionários das equipes administrativas? Existe espaço para a formação desses profissionais?

\section{Gestão educacional: alguns limites e muitas possibilidades}

Atualmente exerço o cargo de técnico de desenvolvimento educacional de duas escolas do Senac/SP - Francisco Matarazzo e 24 de Maio -, com atribuições relacionadas a questões de ordem administrativa e pedagógica. Esta ocupação encontra-se na mesma categoria dos coordenadores ou supervisores pedagógicos. No entanto, o TDE atua na frente formativa da escola como um todo, e não apenas do grupo de docentes. Para além do trabalho com os funcionários da escola, esse profissional também é um articulador de ações entre professores e estudantes, realizando encontros pedagógicos, reuniões com representantes de turmas, articulação de ações que fomentam e resultam no projeto político-pedagógico, formação de professores e encaminhamentos de algumas questões de alunos. Em síntese, o trabalho do TDE se compõe de três dimensões que muitas vezes se misturam: articulação, formação e transformação.

Acerca das dimensões do trabalho do coordenador pedagógico, temos o respaldo teórico de uma pesquisa realizada entre os anos de 2010 e 2011 para a Fundação Victor Civita e para a Fundação Carlos Chagas, na qual Placco, Almeida e Souza (2011) tiveram como objetivo de estudo

identificar e analisar os processos de coordenação pedagógica, em curso em escolas de diferentes regiões brasileiras, de modo a ampliar o conhecimento sobre o coordenador pedagógico (CP) ou função semelhante, quanto às suas potencialidades e limitações e, com isso, subsidiar políticas públicas de formação docente e organização dos sistemas escolares". (p. 226) 
Nessa pesquisa foi possível identificar o trabalho dos coordenadores pedagógicos brasileiros nas três dimensões citadas acima: articuladora, formadora e transformadora. A referida pesquisa intentou analisar dados coletados para interpretar as características do perfil do coordenador pedagógico e suas percepções, assim como as de diretores e professores, quanto a

adesão/rejeição às atribuições da função, dificuldades recorrentes do funcionamento e organização da escola e da formação do profissional do $\mathrm{CP}$ e dos professores que coordena, partindo-se do pressuposto de que o papel central do CP é o de formador de seus professores. (Placco; Almeida; Souza, 2001, p. 226)

O trabalho do coordenador pedagógico está centrado na formação de educadores, todavia, por incorporar o grupo gestor de uma instituição educacional e por compreender a importância de todos os atores sociais para o funcionamento de uma comunidade de aprendizagem, a preocupação acerca da formação dos funcionários administrativos também pode ser evidenciada no cotidiano de trabalho do $\mathrm{CP}$, como é a prática nas escolas do Senac/SP. Mesmo com todas as similaridades da atuação, faz-se necessário considerar que a escola na qual atua o coordenador pedagógico é única.

No cotidiano de trabalho dessa escola do Senac/SP houve a necessidade, no papel de coordenador pedagógico, de articular ações de formação às equipes administrativas por compreender que em alguma esfera do trabalho administrativo todos contribuem à educação. Nesse sentido, o coordenador pedagógico "realiza trabalho com gestão, professores e comunidade também únicos" (Placco, Almeida, Souza, 2001, p. 10).

Sabe-se que para superar os inúmeros desafios do cotidiano escolar há necessidade de trabalho coletivo na escola. Assim, o coordenador pedagógico pode exercer na escola a função articuladora, oferecendo condições para que os professores trabalhem coletivamente as propostas curriculares e organizando espaços para esse diálogo, além de ser convocado a realizar também a função formadora dos professores, no trabalho de formação direta com a equipe docente. É solicitado ainda, em momentos pontuais, para uma função transformadora, que articula mediação pedagógica e interações com os demais atores sociais da escola, visando possibilitar uma melhor aprendizagem aos alunos e, portanto, melhor qualidade na escola.

Consolidando a informação acima, o PPP da escola Senac Francisco Matarazzo/SP expressa que a integração de todos os setores ao trabalho educacional pode favorecer a aprendizagem dos alunos. Nesse sentido, todos os funcionários têm alguma contribuição à aprendizagem, a saber: a equipe de limpeza ao organizar os espaços pedagógicos, a equipe de materiais ao responder as solicitações da equipe docente, a equipe de biblioteca ao promover ações culturais e de incentivo à leitura, a equipe de secretaria ao emitir de maneira pontual uma declaração que afetará a positivamente à vida escolar dos alunos, a equipe de atendimento ao sanar dúvidas de estudantes e responsáveis. Poderia me debruçar e citar inúmeros exemplos cotidianos do trabalho das equipes administrativas da escola Senac/SP, porém, não resta dúvida quanto a importância do suporte administrativo à aprendizagem. 
A pesquisa de Placco, Almeida e Souza (2011) não trata especificamente da atuação dos TDEs nas escolas do Senac/SP, todavia, aborda atribuições e contradições vivenciadas na prática da coordenação pedagógica, sobretudo, sobre alguns desvios no exercício da função coordenadora:

A falta de compreensão sobre limites de sua atuação, considerando-se os eixos articulação, formação e transformação, pode gerar equívocos e desvios no exercício da função coordenadora. Evidencia-se, na pesquisa, que o excesso de atribuições, por parte da legislação, do diretor, professores, órgãos do sistema de ensino, alunos e pais, interfere sobremaneira na atuação que seria específica do coordenador pedagógico, primeiro, porque ele reconhece que essas atribuições são importantes e tende a tomá-las para si e, segundo, porque tem de integrálas às dimensões históricas da profissão, às suas dimensões pessoais e mesmo às suas condições profissionais. (Placco; Almeida; Souza, 2011, p. 766)

No âmbito geográfico do trabalho sobre coordenação pedagógica essa pesquisa apontou que na França, no Canadá, em Portugal, em Moçambique e no Chile há um profissional que articula a formação na escola e que, em alguns casos, ele é também responsável por essa formação. Essa afirmação vinda da pesquisa demonstra a importância da figura representada pela coordenação pedagógica em diferentes países, configurando uma função que norteia a educação no contexto mundial: há um consenso, dentro e fora do Brasil, sobre a importância da coordenação/orientação/supervisão pedagógica no contexto escolar, mesmo quando esta não é feita por alguém destacado nominalmente para essa atividade na escola (Placco; Almeida; Souza, 2011).

Placco, Almeida e Souza (2011) concluem afirmando que a formação continuada em serviço, feita no dia a dia da escola, pode produzir resultados efetivos de melhoria no ensino. Isso corrobora com o que se expõe no desenvolvimento deste trabalho: as ações formativas e o vínculo entre os setores resultando em ganhos a prática pedagógica da escola. Porém, com uma particularidade, as ações aqui apresentadas destinaram-se às equipes administrativas e não à docência.

O discurso e a prática social do Senac/SP de que todos são educadores desloca o papel da escola como lugar onde o conhecimento se concentra na sala de aula para uma vertente mais integrada a comunidade de aprendizagem, posição esta, capaz de "produzir novas práticas e saberes profissionais, interligando, assim, os processos formativos com a organização da gestão escolar" (Canário, 2008, p. 113).

Vale resgatar que o inciso III do artigo 61 da LDB inclui os funcionários administrativa da escola entre os profissionais da educação, referindo-se a eles como sendo trabalhadores em educação. Por mais que os funcionários administrativos desempenhem tarefas relevantes para a escola podem ser esquecidos pela gestão escolar no planejamento de atividades formativas, inclusive, muitas vezes são referidos com a expressão 'não docentes', inferiorizando o lugar social desses trabalhadores no espaço educativo. Conhecer, valorizar e formar esses profissionais pode gerar um aumento na qualidade da educação e do ensino, pois por meio do reconhecimento eles podem se identificar cada vez mais com o trabalho nessa comunidade de aprendizagem e se comprometer com sua atividade laboral. 
Diante de uma gestão que declara que a formação em serviço de todos os funcionários da escola é uma das premissas da instituição e que todos os seus setores fazem parte do processo educacional, pode-se compreender que essa escola em sua função social não poderia excluir de seus encontros formativos dedicados ao desenvolvimento profissional e educacional os funcionários que trabalham em sua construção, asseio, manutenção e organização, enfim, que operam para o seu funcionamento enquanto unidade escolar.

\section{Práticas pedagógicas do Senac/SP}

Desde 2005 a proposta pedagógica ${ }^{2}$ do Senac/SP valoriza o aprender fazendo. Alguns exemplos dessa prática são os ambientes educacionais inovadores $e$ as experiências interdisciplinares contempladas nos projetos institucionais. A proposta tem como base o exercício da ação profissional e, atualmente, a vivência no desenvolvimento de projetos reais e integradores que dialogam com os conhecimentos, as habilidades e as atitudes e valores esperadas no perfil de conclusão do curso. Com isso, pode-se inferir que essa proposta não diferencia momentos de teoria e prática, pressupondo que esses dois elementos são entendidos como indissociáveis no processo de ensino e aprendizagem.

Acerca dos processos avaliativos no Senac/SP eles não se resumem a notas e números em resultados finais, por presumir que o modelo adotado pelo sistema educacional de alguns países com bons índices relacionados ao ensino e a aprendizagem cabe, com algumas adaptações, na proposta pedagógica da instituição. Assim como em escolas da Finlândia, Alemanha, e dos Estados Unidos, o Senac/SP prevê o desenvolvimento de competências, portanto, o aluno é aprovado caso as competências sejam desenvolvidas e evidenciadas no decorrer do curso. Para tanto, utiliza-se a avaliação enquanto processo diagnóstico, contínuo, somativo e instrumento de planejamento. Importante ressaltar que os docentes utilizam diversas estratégias de aprendizagem baseadas nas metodologias ativas e que as competências são orientadas pelo perfil de formação de cada curso.

O conceito de competências abarcado na prática pedagógica do Senac/SP fundamenta-se em alguns prismas teóricos, tais como Perrenoud (2013), Kunter (2013) e Delors (1996).

Perrenoud (2013) compreende a competência como o domínio global de uma situação, enquanto a habilidade refere-se a ações específicas que orientam as operações mentais e as concretas e podem ser elementos a serviço de várias competências. $O$ autor afirma que competência é a "capacidade de agir eficazmente em um determinado tipo de situação, apoiada em conhecimentos, mas sem limitar-se a eles" $(1999$, p. 7). Dessa maneira, a habilidade é uma das bases que sustenta a competência, compreendida como instância integral do fazer.

Numa perspectiva similar, Kunter et. al. (2013) define a competência como as habilidades, conhecimentos, atitudes e variáveis motivacionais que formam a base para 0 domínio de situações específicas. No contexto da educação profissional as competências são aplicadas na diversidade que as profissões exigem.

2 Disponível em: http://www.sp.senac.br/pdf/53727.pdf. 
Essas ideias corroboram com a proposta do Relatório Educação - um tesouro a descobrir (1996), que abrange a educação articulada aos quatro pilares, a saber: aprender a conhecer, aprender a fazer, aprender a conviver e aprender a ser.

Todas essas contribuições somam-se e são apropriadas com algumas adaptações visando uma educação significativa voltada para a formação profissional e para o exercício da cidadania. Avaliação e o desenvolvimento de competências são assuntos rotineiros nas escolas do Senac/SP. Nesse caminho, enquanto coordenador pedagógico, algumas reflexões emergiam, tais como: falamos enquanto escola de educação profissional sobre o desenvolvimento de competências voltadas ao fazer profissional, entretanto, será que os funcionários dos setores administrativos têm ciência das competências de seu trabalho que podem contribuir para o bom andamento de uma escola? Como fomentar o desenvolvimento da competência prestação de serviços educacionais entre as equipes administrativas?

Pelo relato dos alunos sobre os setores da escola, a competência relacionada à prestação de serviços educacionais já estava instaurada nas equipes. Entretanto, como continuar fomentando o diálogo sobre o trabalho em educação e a importância dos funcionários administrativos no espaço escolar? Dessas inquietações, fui convocado, no âmbito formador da atuação do coordenador pedagógico, a desenvolver ações de desenvolvimento às equipes administrativas.

\section{Ações de desenvolvimento focadas nas equipes administrativas: métodos utilizados para a formação}

A primeira ação referida para esses setores aconteceu no ano de 2018 e tratou-se de um projeto de escuta dos funcionários administrativos. O projeto com o título Entre olhares propunha a contratação de um profissional de psicologia que realizaria sessões coletivas com os setores administrativos para que esses trabalhadores pudessem expressar sobre o cotidiano do trabalho. A proposta foi aprovada pela gerência da escola e pudemos contar uma psicóloga durante três meses. Nas conversas agendadas que duravam uma hora para cada setor, essa profissional deixava o espaço aberto para que as temáticas emergissem do próprio grupo, que por trabalhar junto já estava, de alguma forma, integrado. Cada setor pôde participar de, pelo menos, três encontros. O objetivo desse projeto de escuta era a gestão ter um profissional da área da psicologia externo da instituição para interpretar as falas que eclodiam durante as conversas. Ou seja, teríamos alguns assuntos sobre a escola pela visão dos funcionários administrativos facilitados por uma psicóloga.

Algumas das temáticas que emergiram mais intensamente desses diálogos que relacionavam ao trabalho da gestão escolar foram: as propostas de comunicação não violenta já que segundo essas equipes com frequência o erro era apontado e os acertos pouco comentados, a auto liderança, as práticas integrativas entre setores objetivando entender e perceber melhor um o trabalho do outro, e, por fim, um entendimento das questões conceituais sobre o trabalho pedagógico de educação profissional do Senac. Ao final do projeto a psicóloga elaborou um relatório com suas percepções, considerações somadas as falas dos setores e, propôs ainda, pontos de melhoria. O primeiro projeto realizado teve como objetivo a escuta sobre como esses funcionários se relacionam com a estrutura e com as demais equipes da escola. Outros assuntos, tais como promoções 
de cargos, disparidade salarial e plano de carreira também foram abordados, no entanto, essas questões não tem relação com o trabalho do TDE. Nesse sentido, elegi o que era possível melhorar dentro de minhas atribuições.

Como segundo movimento de planejamento e organização para as atividades que, posteriormente, seriam realizadas com os setores administrativos, reuni algumas lideranças dessas equipes, a saber: a coordenadora administrativa, a de biblioteca, a de secretaria e a supervisora de atendimento. Já era observável o empenho dessas líderes no viés educativo de suas funções. Todavia, buscava somar forças para que as ações fossem consistentes e significativas.

Coube a esse grupo de líderes discutir sobre o relatório oriundo do projeto Entre olhares e decidir os temas para a formação dos funcionários administrativos. Foi decidido que dedicaríamos quatro encontros denominados Semana formativa, nos quais desenvolveríamos diversas atividades intentando formar os funcionários administrativos por meio das metodologias ativas.

O próximo passo foi dialogar sobre a proposta com os demais gestores coordenadores de ensino e gerência escolar -, já que era essencial que a escola se preparasse para trabalhar com as ausências dos setores administrativos durante a semana formativa. O grupo de coordenação de ensino também contava com funcionários administrativos que auxiliam na montagem dos cronogramas das aulas, no diálogo com alunos e no suporte necessário à coordenação, e eles seriam convidados para as atividades, já que atuam na esfera da administração escolar.

Utilizamos o espaço da reunião semanal de gestores para abordar a proposta da semana formativa à equipe de coordenação de ensino. A atividade resumia-se a um trabalho de oito horas divididas em duas horas diárias com todos os funcionários administrativos. Houve, no começo, resistência e dificuldade para que todos os funcionários pudessem participar das quatros oficinas de duas horas cada. Notei um desacordo que já suspeitara em conciliar as agendas dos funcionários dos três períodos que a escola permanece aberta: manhã, tarde e noite. Entretanto, todos os coordenadores se comprometeram com a participação de suas equipes nos quatro encontros. Para isso, escolhemos dois horários intermediários entre os turnos para cada atividade, ou seja, cada funcionário teria duas opções de agenda para participar da formação. Não obstante, durante as semanas antecedentes as oficinas algumas questões foram trazidas pelos gestores e também pelos funcionários, tais como: "como vai ficar a cobertura do setor?", "vai ter que se expor? Porque fulana é tímida", "desculpe, mas será impossível a participação dele, a área está cheia de demandas", "a funcionária $X$ participará apenas de um dia, não dos quatro, um está bom", "esse dia ele não precisa participar, não tem a ver com o trabalho dele", "essa semana tem tantas demandas pro setor, ele pode participar numa próxima vez?".

Pode-se induzir que há resistência quanto a formação das equipes administrativas, seja pela dificuldade de articulação do tempo de trabalho com as propostas formativas, ou pela constatação de que esses funcionários são os que menos participam de cursos, oficinas e capacitações realizadas na escola e aberta a todos os funcionários. 
Para que essas equipes pudessem participar, seus gestores precisavam acreditar no significado da formação e destinar tempo para ela, que visa, ao final, uma melhor convivência escolar. Com isso quero dizer que todos, colaboradores e a escola, seriam beneficiados.

A primeira ação proposta para a semana formativa aconteceu no dia 17 de setembro de 2010, abordou a comunicação não violenta e teve a mediação de uma docente da escola que estuda e trabalha as técnicas que auxiliam a promover uma cultura de paz. $\mathrm{O}$ objetivo era o de apresentar conceitos e estratégias que poderiam favorecer um ambiente de trabalho mais amistoso entre os setores administrativos, motivado por práticas discursivas mais saudáveis.

A segunda oficina abordou a auto liderança, realizada no formato de exposição dialogada foi promovida pela coordenadora administrativa. Intentou promover reflexões entre os funcionários sobre a relevância da autogestão de suas carreiras. Nesse sentido, a mediadora apresentou dicas e incentivos ao crescimento profissional.

$\mathrm{Na}$ terceira ação, da qual eu fui o mediador, foi promovida uma prática corpórea, um jogo teatral e uma improvisação cênica sobre as atribuições das áreas administrativas. $O$ objetivo geral das três atividades era o de que todos expressassem algumas dificuldades dos setores e cargos visando melhorar o convívio, a colaboração e integração entre as áreas administrativas.

Por fim, no último dia da semana formativa discutiu-se sobre o conceito de competências profissionais. Por meio de exemplos de práticas dos setores administrativos expusemos algumas considerações sobre as competências, dialogando, assim, com a proposta pedagógica da instituição. Ao final da atividade enviamos um formulário para que todos participantes relatassem suas impressões, percepções sobre as atividades e que sugerissem novas temas para formações futuras.

Ainda no último dia cada funcionário recebeu um documento físico intitulado passaporte formativo. Tratava-se de uma imitação de um passaporte de viagem com a foto do funcionário, seu nome, o setor que atua e o tempo de instituição. No verso o documento tinha a descrição de dez ações ou espaços da escola que o dono do passaporte deveria conhecer e vivenciar, fazendo uma analogia de que conhecer um novo setor ou espaço da escola pode ser uma viagem com muitas descobertas. Os passaportes eram individuais e tinham destinos diferentes para cada setor. Entre os destinos sugeridos estavam: ler um livro, conversar com um docente sobre metodologias ativas, ler um texto sobre educação e comentar com um colega de trabalho, conversar com a direção escolar, realizar um curso da educação corporativa da instituição, dialogar com um coordenador de ensino para compreender um pouco do seu trabalho, assistir à apresentação de um projeto dos alunos, entre outros.

Para cada destino visitado ou ação cumprida o funcionário recebia de seu gestor uma carimbada no passaporte com formato de avião. O propósito dessa ação era o de, por meio da ludicidade, aproximar, ainda mais, os setores administrativos e pedagógicos. 
Figura1 -

Frente e verso do passaporte formativo.
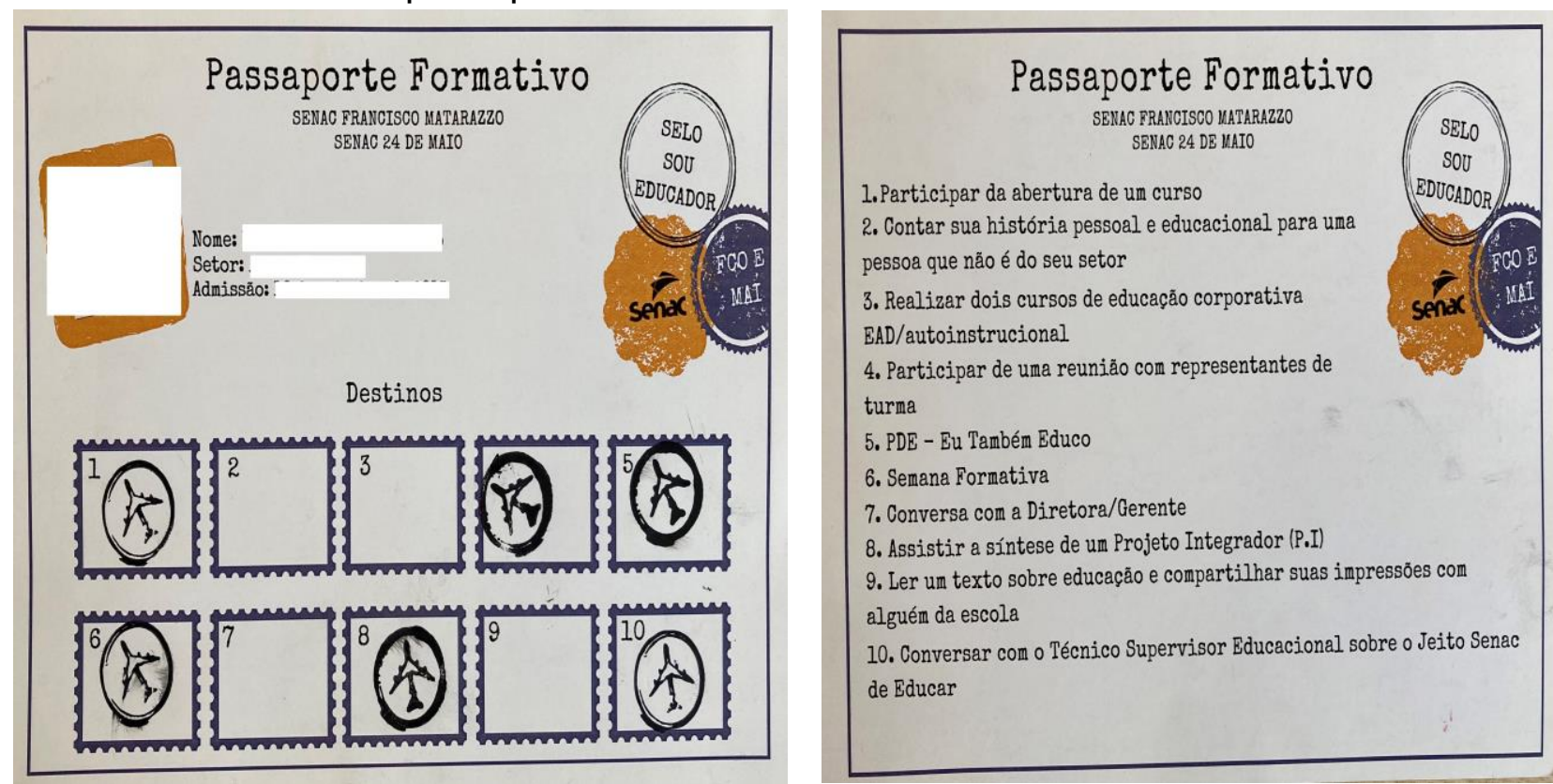

Fonte: autor.

Outra atividade que fomentou a competência prestação de serviços educacionais nas equipes administrativas foram as ações de revitalização do PPP da escola. Essas atividades foram vivenciadas no final do ano de 2019. Vale destacar que o primeiro PPP foi desenvolvido no ano de 2016 e finalizado no segundo semestre do ano de 2017. Nesse documento a escola expressa sobre sua prática atual e as suas metas de futuro, contemplando um plano de ação.

Mensalmente as escolas realizam um encontro pedagógico com a participação de todos os setores da escola. A proposta do encontro de dezembro de 2019 era a de refletir sobre o entorno da instituição visando a dialogar sobre o PPP. Foi orientada durante a reunião uma caminhada por espaços culturais, educativos e comércios do bairro. Sugeriuse que durante o passeio fosse mantido o foco nas possibilidades que a escola pode ofertar à comunidade, aos trabalhadores, as instituições e ao varejo por meio de ações educativas, cursos e projetos. Tivemos ainda como missão desse encontro identificar quais eram os novos desafios da escola Senac que estariam descritos na revitalização do PPP. O percurso pelo bairro, as conversas entre funcionários de diferentes setores e o olhar para o futuro da escola pôde gerar sensações de pertencimento e responsabilidade nos envolvidos durante toda a reunião.

Por vezes, desafios aparentemente simples podem gerar resultados e novos sentidos à prática dos funcionários. Este foi um dos aprendizados extraídos de um convite feito pela direção/gerência escolar às equipes administrativas em outra ação. Foi recomendado pela gerente da unidade escolar que fossem pintadas as paredes dos sete andares da escola. Porém, o poder de escolha das cores e tonalidades foi dado aos funcionários dos setores de materiais, limpeza, manutenção, entre outros. Com isso criouse um sentimento de pertencimento para essas equipes. Vale destacar que essa atitude pode ser inscrita no âmbito de uma gestão democrática. Ações como esta trazem à tona a valorização e o reconhecimento de alguns saberes desses trabalhadores.

v. 10

n. 19

e65003, p. 1-13

2021 
A última atividade realizada foi incorporada dentro do projeto chamado Chá pedagógico, realizado mensalmente nas escolas. Trata-se de um encontro de duas horas, no qual além de oferecermos café, chá e bolachas, debatemos temáticas relevante à educação. No mês de outubro de 2019 o Chá pedagógico foi mediado por funcionários da equipe de limpeza. Frisa-se que essa ação foi planejada de acordo com as orientações e o suporte da gestão pedagógica, visto que essa equipe não está habituada a realizar palestras e momentos expositivos para um grande grupo. Nesse encontro a equipe de limpeza desenvolveu atividades para funcionários de todos os setores da escola, enfatizando alguns saberes e promovendo reflexões sobre a coleta seletiva de materiais e resíduos. O intuito desse chá era o de reforçar a importância de atitudes sustentáveis aos funcionários. Tivemos a participação de mais de trinta pessoas, o que deixou os mediadores um tanto nervosos, apesar disso, vivenciamos duas horas de aprendizados por intermédio de atividades dinâmicas. Para além do trabalho voltada para a sustentabilidade e para o meio ambiente, eles e elas da equipe de limpeza, exercitaram alguns dos aspectos educativos do trabalho, o intercâmbio de conhecimentos entre às áreas.

\section{Considerações finais}

O coordenador pedagógico, no Senac/SP representado na figura do TDE, tem, entre as diversas possibilidades de atuação, a de fortalecer a escola como um espaço de aprendizagem para todos que convivem nela, permitindo uma verdade inserção das pessoas na comunidade escolar. Na esfera formadora do trabalho do TDE faz-se importante assumir "o compromisso o homem concreto, com o ser mais deste homem" (Freire, 1980, p. 25).

Acredita-se que as pessoas que estão em cargos de liderança e de gestão em instituições escolares são capazes de coordenar ações educativas incorporando as equipes administrativa na posição de agentes participantes ativos do cotidiano escolar. Seja promovendo reuniões dialógicas, atividades formativas ou simplesmente escutando os funcionários e agindo a respeito dessa escuta. Enfim, objetivando a formação em serviço de todos os trabalhadores da instituição.

Não resta dúvida de que a escola, com todas as dificuldades que as pessoas que trabalham nela tenham no cotidiano profissional, ainda é um braço democrático da sociedade, presente em comunidades e territórios que poucos órgãos e serviços públicos assistem. Paulo Freire (2006) expressa que a escola deve ser um lugar de trabalho, de ensino, de aprendizagem, portanto, um espaço privilegiado para pensar e agir. Para além de formar, faz-se de suma importância aprender com os conhecimentos empíricos adquiridos pela experiência das pessoas que trabalham nos setores administrativos. A troca de conhecimentos e habilidades entre os setores também foi um dos objetivos das ações apresentadas neste trabalho. Nesse sentido, as equipes das escolas puderam ensinar umas às outras.

A equipe gestora pode aprender constantemente se estiver disposta a conhecer as demais equipes, os trabalhadores e o cotidiano dos setores. É possível aprender, por exemplo, observando o cuidado com que limpam e organizam as salas de aula ou valorizando um funcionário que auxilia o trajeto de uma pessoa com deficiência visual. Pode-se aprender com uma pergunta reflexiva sobre o curso vinda da equipe de

\begin{tabular}{|l|l|l|l|l|l|}
\hline Regae: Rev. Gest. Aval. Educ. & Santa Maria & v. 10 & n. 19 & e65003, p. 1-13 & 2021 \\
\hline
\end{tabular}


atendimento, afinal, esses funcionários são a porta de entrada das pessoas na escola e têm conhecimento sobre o que buscam os alunos. Pode-se aprender com a equipe de recursos humanos que, com didática e atenção, ensina sobre o preenchimento do registro de ponto e as implicações leis do documento. Somos capazes de aprender com a equipe de manutenção que orientam sobre os cuidados necessário com as salas de aula, com a equipe de tecnologia da informação quando formatam e dão conselhos aos monitores de informática sobre a utilização dos notebooks. Consegue-se aprender quando a equipe docente apresenta uma nova atividade ou quando se acompanha uma experiência em sala de aula. Enfim, aprender é inerente ao trabalho numa escola, entretanto, reconhecer os aprendizados e destinar tempo e espaço para que os saberes emerjam pode ser uma grande oportunidade para que as escolas sejam, cada vez mais, espaços de intercâmbio de conhecimentos, habilidades, atitudes e valores.

\section{Referências}

AZANHA, José Mário Pires. Educação: alguns escritos. São Paulo: Companhia Editora Nacional, 1987.

BRASIL. Lei n. 9.394, de 20 de dezembro de 1996. Disponível em: http://www.planalto.gov.br/ccivil 03/leis/19394.htm. Acesso: 27 mar. 2021.

CANÁRIO, Rui. Formação e desenvolvimento profissional dos professores. Lisboa: Ministério da Educação, 2008, p. 133-148.

CIMEAC. A educação como projeto de corresponsabilização: práticas, saberes e mudança social no século XXI - entrevista com José Pacheco. Cadernos Cimeac, Uberada, v. 6, n. 2, 2016, p. 5-14.

DELORS, Jacques et al. Educação: um tesouro a descobrir. Disponível em: https://unesdoc.unesco.org/ark:/48223/pf0000109590 por. Acesso em: 18 mar. 2021.

FREIRE, Paulo. Educação e mudança. São Paulo: Paz e Terra, 1979.

FREIRE, Paulo. Conscientização, teoria e prática da libertação: uma introdução ao pensamento de Paulo Freire. São Paulo: Moraes, 1980.

KUNTER, Mareike et. al. Professional competence of teachers: effects on instructional quality and student development. American Psychological Association: Journal of Educational Psychology. Washington, v. 105, n. 3, 2013, p. 805-820.

PERRENOUD, Philippe. Desenvolver competências ou ensinar saberes? A escola que prepara para a vida. Porto Alegre: Penso, 2013.

PLACCO, Vera Maria Nigro de Souza; ALMEIDA, Laurinda Ramalho de; SOUZA, Vera Lucia Trevisan. O coordenador pedagógico e a formação de professores: intenções, tensões e contradições. São Paulo: FVC, 2011.

PLACCO, Vera Maria Nigro de Souza; ALMEIDA, Laurinda Ramalho de; SOUZA, Vera Lucia Trevisan. Retrato do coordenador pedagógico brasileiro: nuanças das funções articuladoras e transformadoras. In: PLACCO, Vera Maria Nigro de Souza; ALMEIDA, Laurinda Ramalho de; SOUZA, Vera Lucia Trevisan (org.). O coordenador pedagógico no espaço escolar: articulador, formador e transformador. São Paulo: Loyola, 2015, p. 9-24.

SCHMIDT, Leide Mara. A desconhecida dinâmica da escola. In: RIBAS, Mariná Holzmann (org.). Formação de professores: escolas, práticas e saberes. Ponta Grossa: UEPG, 2005. 
Caio Cesar Silva Nascimento é técnico de desenvolvimento educacional no Senac/SP.

Orcid: https://orcid.org/0000-0002-5294-4359.

Endereço: Alameda Barão de Limeira, 1195/32 - 01202-003 - São Paulo - SP Brasil.

E-mail: caionasser1@gmail.com.

Critérios de autoria: Caio Cesar Silva Nascimento concebeu a ideia, analisou os dados e escreveu o manuscrito.

Recebido em 29 de março de 2021.

Aceito em 6 de setembro de 2021.

(c) (i) (8) $\Theta$ 